Article

\title{
Toward a Model of Strategic Influence, International Broadcasting, and Global Engagement
}

\author{
Kenneth L. Hacker * and Vanessa R. Mendez \\ Department of Communication Studies, New Mexico State University, Las Cruces, NM 88003, USA; \\ E-Mails: khacker@nmsu.edu (K.H.), vamendez@nmsu.edu (V.M.)
}

Submitted: 2 June 2015 | Accepted: 23 November 2015 | Published: 4 May 2016

\begin{abstract}
This article explores how strategic communication, public diplomacy, international governmental broadcasting, and social media networking can be brought together in a system of strategic influence and global engagement. The analysis offers a contrasting approach to various views of public diplomacy or strategic communication which privilege one form of governmental influence over others and treat partial aspects of national persuasion as complete pictures of government communication aimed at foreign audiences. Because so much of public diplomacy literature today emphasizes social media, it is necessary to determine how specific tools of influence such as international broadcasting, can be used in ways that fit new thinking in public diplomacy as well as continuously emerging new media ecologies.
\end{abstract}

\section{Keywords}

international broadcasting; public diplomacy; social media; strategic communication; strategic influence

\section{Issue}

This article is part of the issue "International Broadcasting and Public Diplomacy in the 21st Century", edited by Gary D. Rawnsley (Aberystwyth University, UK).

(C) 2016 by the authors; licensee Cogitatio (Lisbon, Portugal). This article is licensed under a Creative Commons Attribution 4.0 International License (CC BY).

\section{Introduction}

This article explores how strategic communication, public diplomacy, international governmental broadcasting, and social media networking can be brought together in a system of strategic influence and global engagement. The analysis offers an approach to public diplomacy and strategic communication which contrasts with other approaches that privilege one form of governmental influence over others. Some of those approaches treat partial aspects of national persuasion as complete pictures of government communication aimed at foreign audiences. A major problem with both the study of and the implementation of government communication such as international broadcasting is the recurring disagreements about terminology and which governmental entities should conduct specific forms of influence such as public affairs and information operations. A related problem is that new media today as well as old media like radio and TV, are no longer isolated channels of communication, but are part of media systems or ecologies. Because so much of public diplomacy literature today emphasizes social media, it is necessary to determine how specific tools of influence such as international broadcasting, can be used in ways that fit the new thinking in public diplomacy and strategic communication in all areas of communication directed to other nations (national influence) from the United States Government (USG). Thus, the main problem we address here is the fragmented nature of USG influence and the lack of theory guiding present proposals for solving the problem.

We begin by examining the history of American national influence and the emergence of public diplomacy and strategic communication. We then note how power, influence, and national interests are all at stake, as both public diplomacy and strategic communication serve them. We then move to the role of international broadcasting and its possible turn away from a propaganda function, toward a relational one. This includes noting the need for international broadcasting to integrate mass communication with social media and digi- 
tal communication. Following that, we use Rhonda Zaharna's arguments about network diplomacy and collaborative public diplomacy, along with Manuel Castells' communication power theory, to build a model of strategic influence and global engagement that can guide international broadcasting into some new functions. The study concludes with an argument about how the model can be used to focus research and debates about ways that international broadcasting can serve both strategic influence and global engagement goals.

Strategic communication (SC) is generally conceptualized as communication done by the USG for purposes of enhancing national image and improving relations with other nations. The term, as applied to political communication, originated with the Department of Defense in 2004. ${ }^{1}$ Public diplomacy (PD) is a kind of strategic communication in some views and an alternative to SC in others. The PD term originated in academia and is carried heavily by the State Department (Cull, 2009). Both of these terms refer to national political influence directed toward other nations. Overall, there are two camps of national influence that appear to be talking past each other-strategic influence done by military and intelligence sources, and relational networking for public diplomacy. According to Gregory (2014), public diplomacy is defined as nation-states and other political entities analyzing cultures, attitudes, and behaviors; constructing and managing relationships; and doing persuasion that promotes their interests.

Four terms are defined here for the clarity of the argument to be developed. SC generally refers to either all government persuasion aimed at other nations or populations or to the governmental persuasion more likely done by the military than by the diplomacy community. PD refers to persuasion aimed at other nations or populations that is more likely to be done by the diplomacy community than by the military. Strategic influence refers to governmental or national communication done by any agency or agencies of the government that is designed to change attitudes of other populations. Information operations (IO), while sometime defined as military kinetic information assurance and attack only, actually includes persuasion work such as counter-propaganda (Armistead, 2010). ${ }^{2}$ Despite parochial efforts to keep these separate, recurring conceptual intersections make clean separations impossible. This is because the history of American national influence efforts has always involved both strategic influence and cultural engagement, even if new labels have been attached to the same wine bottles. As we move toward a discussion about international broadcasting, it is assumed here that both social media and

\footnotetext{
1 http://fas.org:8080/irp/agency/dod/dsb/commun.pdf

${ }^{2} 1 \mathrm{O}$ is sometimes incorrectly denoted as an activity or domain limited to military operations, when in fact, 10 is also practiced by the intelligence community (IC).
}

international broadcasting have specific purposes for political influence and cultural networking.

Soft power is a concept used by scholars to discuss influence which is based on attraction and persuasion as opposed to influence based on coercion or force (hard power). While hard power can work to stop violent actions at times, soft power can work to build relationships and cultural affinities (Nye, 2004). Smart power is used to define uses of both soft power and hard power in relation to contextual factors. As the uses of smart power can be viewed as a system of influence using both hard and soft power as needed, a system of smart diplomacy (with appropriate firewalls) can combine soft diplomacy and hard diplomacy. Consistent with the soft power concept, soft diplomacy is intended to be non-aggressive and focused on relationships and conciliatory communication. On the other hand, hard diplomacy, like hard power, is intended to be aggressive and one-sided with its messages. Hard diplomacy can be used in conjunction with force against violent agents. Examples of hard diplomacy are coercive diplomacy, information operations, counterideology/narrative, and refutation broadcasting. Soft diplomacy includes cultural diplomacy, network diplomacy, exchanges, public affairs, and objective broadcasting. It can be used to build soft power attraction and positive national images in conjunction with traditional diplomacy. It may be possible to locate public affairs, cultural networking, exchanges, and some broadcasting and social media networking within the goals of what is now accepted as public diplomacy. Hard diplomacy is likely to involve communication that pressures others into compliance. In contrast, soft diplomacy can be seen in relationship building and cultural exchanges. The concept of soft diplomacy is consistent with the goals of soft power. The concept of smart diplomacy offers an alternative to choosing between either a soft diplomacy (relational) or a hard diplomacy (informational) for situations requiring a mix of both approaches to influence. Smart diplomacy is defined here as diplomacy that uses either hard or soft diplomacy for varying persuasive needs. Clearly, Nye's (2004) concept of smart power provides an analogue for the concept of smart diplomacy offered here.

Global engagement is defined here as two-way dialogue between the USG and other nations or populations, along with more deliberation and debate as opposed to more push-down and one-sided persuasive messages (Snyder, 2013). The Obama administration's approach to global engagement has stressed working with other nations to address shared global issues as well as engage foreign audiences to understand American national interests (Lord \& Lynch, 2010). The White House approach to global engagement includes negotiation, dialogue, public diplomacy, and cultural networking. The White House (2010) states "Our communication and engagement with foreign audiences 
should emphasize mutual respect and interest. The United States should articulate a positive vision...and engage foreign audiences on positive terms" (p. 6). Mutual respect and interests should avoid the problems that Arndt (2005) notes with cultural communication that treats America as the teacher and other cultures as learners.

In building a model of strategic influence and global engagement, we argue that models of mass communication and message diffusion are weak in their ability to explain how international broadcasting and new media can be used for public diplomacy. These models form the foundation of many current arguments about PD and SC. We prefer to employ network theories, specifically, Zaharna's model of network diplomacy and Castells' theory of communication power. These perspectives provide a sound basis for developing theoretical propositions regarding the role of social media used in conjunction with broadcasting channels like Voice of America (VOA). A perspective that unifies strategic communication and public diplomacy as well as mass communication, international broadcasting, and networking communication is presented as a model of strategic influence and global engagement. Scholars have recently noted that "Despite the proliferation of contemporary international broadcasting, research about it lacks theoretical development" (Youmans \& Powers, 2012, p. 2149). While no single model can be expected to unify everything important about either public diplomacy or international broadcasting, important progress can be made by offering new models for testing, debate, and heuristic value.

Strategic influence, as used in this article, refers to a combination of strong public diplomacy and strategic communication. It is designed to not only inform, but also to change attitudes (Waller, 2009). Sometimes, this means aggressive communication that counters the communication of other nations or organizations (Waller, 2009). Changing attitudes, commonly known as persuasion, is not seen here as inimical to cultural relations or cultural engagement. Both are parts of a larger system of national influence. National influence is by nature political and serves the national interests and national security concerns of the source nation.

The argument presented here brings together what some scholars in the past separated-strategic communication being done by the military and public diplomacy being done by the State Department. ${ }^{3} \mathrm{~A}$ recognition of the fact that the Department of Defense (DOD) can do public diplomacy and the Department of State (DOS) can do strategic communication, shows that this dichotomy has lost its usefulness. Strategic

\footnotetext{
${ }^{3}$ We recognize the fact that some scholars use SC as an umbrella term for all USG influence (Waller, 2009). We find it more useful to view SC and PD as two forms of national influence.
}

communication has been used by some experts as an umbrella term that indicates a "whole of government" approach to "unified" or "integrated" communication sent to other populations by the USG. Strategic communication and its public diplomacy are designed to achieve the following national security objectives of the USG: championing human dignity; strengthening alliances against terrorism; defusing regional conflicts; preventing threats from weapons of mass destruction; encouraging global economic growth; and transforming America's national security institutions to meet the challenges and opportunities of the twenty-first century. It has become evident that when the U.S. military becomes more involved in civilian affairs, the SC versions of PD predominate more than in areas of conflict than where the military is less involved. ${ }^{4}$

SC and PD stem directly from national security policies. Before terms like SC and PD were used by the USG, it was common to talk about the government providing information, conducting ideological warfare, doing political warfare, and designing campaigns to "win hearts and minds." SC, PD, and IO shared the goal of winning battles not only with military force but with so-called "soft power" or non-military means of persuasion and influence. Because these forms of communication work in parallel, one might see 10 as the hard side of soft power, as noted by some 10 scholars (Armistead, 2010). One key issue regarding SC today is how much the component disciplines and areas of responsibility should be coordinated or integrated. Coordination does not have to include integration but an integrated approach to national influence can assure that all the various forms of USG communication aimed at other populations are congruent in goals, values, themes, and message strategies.

There is a dual nature of SC and PD that is important to recognize. The twin goals of national influence are a) to promote a better national image and relationships with others, and b) to counter false or negative information coming from other political sources. A current example is Japanese national influence. Most of what Japan does with public diplomacy has the objective of building soft power, or specifically, of employing cultural diplomacy to foster better international relations. One tool employed by Japan to do this is the Japan Foundation. Yet, there is also the accompanying goal of offering an alternative to another nation's soft power outlets, those of China which are known as the Confucius Institutes (Snow, 2014). The USG has many outlets of international broadcasting

\footnotetext{
${ }^{4}$ It is important to note that some of legal strictures on State Department PD do not apply to Department of Defense or military broadcasting. For example, armed forces broadcasting, intended for internal American audiences, is overseen by the DOD, not the BBG. http://afrts.dodmedia.osd.mil/facts/2. pdf?v $=1$
} 
that clearly serve the constant goals just described. For instance, after $9 / 11$, broadcasting was intended to win hearts and minds of those who might be susceptible to anti-American messages (Snow, 2014).

International broadcasting sources like the British Broadcasting Corporation (BBC), Japan's NHK World, Deutsche Welle, and the Voice of America (VOA), are careful to keep perceptions of credibility high while also being diligent in not contributing to any endangerment of national security. Because they are arms of governmental policy and communication offices, these broadcasting sources need both objectivity and service to foreign policy goals of their respective states. Sometimes, as in the case of USG sources like Al Hurra in the Middle East, the central goal of USG broadcasting is to counter the anti-American broadcasting of other nations or groups in the region (Snow, 2014). In a way, international broadcasting is held to the standard of objectivity while also being expected to present American interests in the best light and countering anti-American messages. This is akin to what is continuously expected of both SC and PD.

America's VOA outlet, often compared to the BBC for its objectivity, has become embroiled in the tensions between objectivity and state support we have been discussing. In 2001, the VOA had interviews with violent extremists. The network did this to fulfill its goals of balance, objectivity, and credibility, but critics argued that in times of national crises, international broadcasting should help the nation advocate more than strive to be balanced. In the words of one of these critics, William Safire (2001), "Even in peacetime, news credibility does not flow from splitting the moral difference between good and evil" (para. 14). The State Department apparently pressured the Broadcasting Board of Governors (BBG) to have the VOA back off from interviewing Mullah Mohammed Omar, a key Taliban leader.

The strategic goals of the BBG today are stated as providing accurate and objective news, but also as telling America's story to the world (Price, Has, \& Margolin, 2008). The BBG says that it "supports United States national interests through its mission to inform, engage, and connect people around the world in support of freedom and democracy" (BBG, 2013, p. 1). The BBG (2015) claims a weekly audience of approximately 215 million people. BBG broadcasting services include Voice of America (VOA), Office of Cuba Broadcasting (OCB), Radio Free Europe/Radio Liberty (RFE/FRL), Radio Free Asia (RFA), and the Middle East Broadcasting Networks (MBN). ${ }^{5}$ The BBG is distributing programs in 61 languages to more than 100 countries each week (BBG, 2015). This includes the old media of radio and TV, as well as the new media, including mobile phones and

5 http://www.bbg.gov/wp-content/media/2015/03/BBG_Fact sheet_v18.pdf social media. The BBG is independent but is still a federal agency that supervises all government civilian-run international media (Mull \& Wallin, 2013). All international broadcasting networks are concerned with national security and are not just sources of news. International broadcasting networks are also a source of strategic influence, however subtle or blatant. ${ }^{6}$ This function is consistent with the clear guidelines for the BBG and its international broadcasting that are set out in legislation and policies. American international broadcasting is required to provide all sides of important issues and USG policies, to provide opportunity for debates about the policies, while also advancing USG foreign policy by informing foreign audiences "in a balanced and objective manner" (Weed, 2014, p. 17). Connecting international broadcasting to foreign policy involves an examination of national security concerns that guide the formation of government policies.

\section{The National Security Context for Strategic Influence}

National security policies must precede strategic communication and public diplomacy policies if the latter are to serve national security interests and goals. The central goal of American national security is to ensure the physical safety of the nation and protecting its national interests. The term "national security" became increasingly common in political discourse after World War II. It is a concern for presidents and statecraft that involves not only military matters, but also security in diplomacy, economics, and national identity (Mastapeter, 2008). An essential part of national security is national power and such power can be viewed as economic, technological, military, diplomatic, and relational. American national security communication has always included discourse that promotes its values and projects it power. While the forms of USG communication are reinvented, re-conceptualized, and reorganized frequently, the underlying mission of bolstering national security remains constant.

As threats to national security constitute a spectrum of threats ranging from conflict to extreme violence and war, strategies for dealing with these threats also have a spectrum ranging from diplomacy and negotiation to all-out war. An implication here may be that choices made by the USG about power options might lead to choices made about what types of SC and PD are optimal for particular circumstances. For example, recent Presidents (Bush and Obama in particular) have chosen approaches to national power that project American power and dominance in certain regions so that SC and PD are guarding the national security ob-

\footnotetext{
${ }^{6}$ This should not imply that influence equates with propaganda. Refuting falsehood can be done with facts and truthful clarification of policies (Arndt, 2005).
} 
jectives and political interests of the White House.

Some observers note that because national influence (SC, PD) is born in considerations of power and political interests of a source nation, it is necessary to have influence that does not shy away from or deny political strategies (Lord \& Lynch, 2010). Whether Thucydides giving an account of the Peloponnesian War, Julian Corbett distinguishing German military strategies from British ones, or contemporary Israel contemplating aggressive actions by other Middle Eastern states, political and military theorists have seen the connections between history, geography, cultural, and nationnation interactions (Mahnken, 2006). The fact that the United States is the most powerful state on the planet affects how it relates to other nations and how it conducts national influence. Strategic culture is a nationstate's set of shared beliefs and modes of behavior that shape its collective identity and method for securing national security (Mahnken, 2006). For example, American strategic culture is imbued with exceptionalism (Mahnken, 2006). This affects how the nation communicates.

Along with the study of strategic cultures as background knowledge for effective SC and PD, it is necessary to consider complex interdependencies in how nations and cultures relate to each other (Freedman, 2013). This includes the study of culture, but also politics, technologies, economics, geography, and intelligence (Gray, 1999). Strategic and systems thinking should accompany SC and PD planning and evaluation, yet there is scant evidence of this now occurring or being recommended in the myriad of reports on national influence. Systems thinking looks at multiple variables relevant to a problem and how changes in those variables affect each other and the entire system (Freedman, 2013).

In addition to the need for basing national influence on political strategies that serve national interests and national security, there is a need for historical realism in narrating the position of the United States in world opinion. It is presently too common to cite the decline of America's national image in the recent past, free of any long-term historical perspective. For example, historians have noted that criticisms of Americans by Europeans go back to the colonial days. We know for example that while Alexis de Tocqueville praised certain aspects of American life, he was also very critical of other aspects such as what he called the "tyranny of the majority." The founding fathers of America like Thomas Jefferson portrayed the new nation as a "chosen country" (Sanders, 2011, p. 15). In the 19th century, English, German, Russian, and French authors were mocking Americans as being vulgar and focused mainly on making money (Sanders, 2011). This kind of historical context is important for understanding why SC and PD professionals struggle so much with how to improve America's image in the world. Critical views of the
United States did not originate with $9 / 11$ or the invasion of Iraq despite the fact that recent operations have increased negative attitudes toward the nation.

\section{The Need for Strategic Influence}

Some observers like Admiral Mike Mullen appear to believe that good policies automatically generate good relations among nations, thereby erasing the need to keep struggling over meanings and strategies for SC. Mullen (2009) argued: "To put it simply, we need to worry a lot less about how to communicate our actions and much more about what our actions communicate. Each time we fail to live up to our values or don't follow up on a promise, we look more and more like the arrogant Americans the enemy claims we are" (p.4). Such thinking can lead to strong criticism of systematic government influence. Some reject or resist strong systematic influence because they believe that it has so often failed in the past. A continual challenge to strategic influence has been the steady flow of criticisms from other nations, even allies, of American presence in other places in the world. It appears that dodging serious discussion about policy concerns with traditional public relations techniques can add fire to the accusations of bad policies and bad intentions (Sanders, 2011).

We noted earlier, there are competing definitions for most terms related to national influence. For example, Snow (2014) observes "There is no one definition of public diplomacy in the literature....Educational and cultural exchange have been a public diplomacy mainstay, as is an international broadcasting operation that targets a global population" (p. 4). It is possible that some of the confusion about terminology in SC and PD is related to a weak sense of historical progression for how Americans respond to national identity, compete with other ideologies and have a reluctance to have strong propaganda in times of peace. Thus, we now look at some historical background.

\section{Historical Background}

Throughout history, nations have used communication to promote their interests and to warn adversaries about their commitment to their national security. Colonial Americans, in their struggle for independence from England, used personal diplomacy, letters, intelligence, pamphlets, and the Declaration of Independence, to cajole potential supporters in France, Spain, Canada, and other nations to support their cause (Waller, 2008). France promoted its revolution in the 18th century by sending messages directly to citizens of other nations. Like the Alliance Francaise origins in 1883 , other nations such as Italy and Germany, established institutes for promoting their cultures. America was generally reluctant to establish a permanent and large-scale ideological agency. Despite its early com- 
mitment to cultural diplomacy, the United States is wary of establishing large-scale ideological agencies.

World War I brought the emergence of the Committee on Public Information (CPI). The CPI was the first centralized propaganda agency of the USG. In 1917, President Woodrow Wilson appointed George Creel, a journalist and campaign consultant for Woodrow Wilson's re-election campaign of 1916, to be the director of the CPI. Creel targeted both foreigners and Americans to support the war. Wilson and Creel worked closely together to frame the U.S. entry into the war as idealistic and imperative. Creel framed those opposed to the war as traitors. Creel knew that what he called information was propaganda, but he argued that even information presents what the government wants people to believe. The CPI portrayals were to be based on facts and the public should make the desired conclusions and decisions by examining the evidence presented to them. Creel used the word "information" rather than "propaganda" because he believed the latter was "purposeful lying" (Arndt, 2005, p. 28). It is interesting that Creel once remarked that "people do not live by bread alone; they live mostly by catch phrases" (Freedman, 2013, p. 337). The first official propaganda agency for America was steeped in strategies and tactics of one-way framing and persuasion.

America shut down its CPI propaganda machine in 1919 (Tuch, 1990). During the post-war years, Hitler ramped up Germany's propaganda, in part, by learning from CPI tactics (Pratkanis \& Aronson, 1991). Russian Bolsheviks made propaganda a major part of their foreign policy strategies. The British BBC was established in 1922. The Dutch began their international broadcasting in 1927, the French in 1931, and the British in 1932. The fascists in Italy and Germany had unified ideological operations up and running ahead of the United States. The Office of War Information (OWI) was started by President Roosevelt in 1941 and the VOA began in 1942 (Sorenson, 2006). The OWI was created to help define the role of the United States in the world. Russia had already made Radio Moscow an international broadcasting network by the beginning of World War II (Dizard, 2004). Nazi Germany had developed a strong radio propaganda system and Britain had its British Broadcasting Corporation (BBC) which began broadcasting international radio programs in 1932 (Dizard, 2004).

Before World War II, the United States was the only major power that did not have a strategic influence or public diplomacy bureaucracy. In 1938, the State Department established a Division of Cultural Relations and programs targeted at the people in Latin America. In 1940, Nelson Rockefeller became the leader of the newly created Office of the Coordinator of InterAmerican Affairs. Some political leaders thought that truth was more important than propaganda. There were leaders in the military who believed that wars are fought with weapons and not with words. This changed with the Japanese attack on Pearl Harbor in 1942. Ideological operations became part of war mobilization. While President Roosevelt had witnessed the actions of the CPI during World I and despised that kind of centralized and iron-fisted propaganda, Nelson Rockefeller did not mind blending cultural relations with propaganda and intelligence (Arndt, 2005). Propaganda was enjoined with soft-power culturalism.

All of the nations that fought in World War II used strong propaganda as part of their means of doing battle (Taylor, 2003). British propaganda against the Nazis used some of the same themes used in World War I, such as the Nazis being ruthless and hateful "Huns." While President Roosevelt had officially opposed propaganda, he came to endorse the use of Hollywood movies to support America's war against the Axis powers. Roosevelt commented "The motion picture industry could be the most powerful instrument of propaganda in the world, whether it tries to be or not" (Taylor, 2003, p. 229). Both Winston Churchill and Franklin Roosevelt spoke to their respective populations with popular fireside radio "chats." These radio speeches were designed to fortify domestic confidence in the war efforts.

The end of World War II brought declining interest in ideological warfare, but it increased again with the emergence of the Cold War. Advocates of strong public diplomacy during the Second World War included Nelson Rockefeller and William Donovan, both of whom saw strong strategic influence as necessary to combat the propaganda of the Germans (Arndt, 2005). Both men were outspoken leaders who advocated stronger reactions by the United States to the Nazi regime of Germany. Donovan worked on establishing the espionage service that later became the Central Intelligence Agency ( $\mathrm{CIA}$ ) and a project to use propaganda to support British resistance to the Germans. Rockefeller lobbied for greater American efforts in Latin America in order to counter German influence there. His efforts led to radio broadcasts directed into Latin America. President Franklin Roosevelt appointed Donovan as head of the Office of the Coordinator of Information (COI). The COI collected intelligence but also conducted information operations designed to diminish the morale of the Germans. The COI included a unit known as the Foreign Information Service (FIS). The FIS was an effort of William Donovan and President Roosevelt to expand ideological operations far beyond the influence campaign directed into Latin America. In 1942, the FIS initiated radio broadcasts with the name Voice of America. According to Nicholas Cull (2009), the intelligence community (IC) developed the early radio capabilities for the U.S. such as VOA.

While many people questioned the need or desirability of propaganda for a domestic audience, others also questioned the idea of propaganda for other na- 
tions during times of peace. Ralph Block (1948), a State Department official at the time wrote that "It is possible that more Americans approve of the use of the atomic bomb in defensive warfare than approve of the use of propaganda to forestall war" (p. 678). The White House shut down the OWI in less than two weeks after the surrender of Japan. President Truman transferred the functions of the OWI to the State Department, where it became part of the Bureau of Public Affairs. The functions of the Office of Strategic Services (OSS) were transferred to the War Department, including overt psychological operations. One thing to note in this brief historical foray is the tendency of the USG to back off from aggressive communication during peacetime and to have disagreements about how and where to locate and manage national influence activities.

Three key cultural tools for Germany's propaganda chief Josef Goebbels, were radio, news print, and film. Radios were taken over by the Nazis who viewed propaganda as fighting on a new kind of battlefield. The Nazis combined public relations in other nations with their propaganda efforts. There were 300 Germanlanguage newspapers in other countries. They had financial holdings in 350 newspapers published in other languages. They also had a news service called Transocean that mixed objective news with propaganda such as anti-British messages. Goebbels hired a pioneer Ivy Lee of the American public relations industry to help him with his propaganda. Ivy Lee helped to do image repair for John D. Rockefeller (Hart, 2013). Ivy Lee had worked with the CPI during World War I. Lee was paid $\$ 33,000$ per year to help make Hitler popular among the German people (Manvell \& Fraenkel, 2010).

There was no commitment to truth in Nazi propaganda, just as there is no commitment to truth in proterrorist propaganda today. President Roosevelt was accused of serving the Jews. The sinking of the British passenger ship, the S.S. Athenia, was said to have been done not by the Germans (they really did it) but by British leader Winston Churchill. Goebbels was controlling German radio broadcasting by 1933 . Listening to radio broadcasts critical of Germany could result in imprisonment. By 1942, Nazi radio broadcasting was reaching out in nearly 30 languages. German Nazi broadcasting even reached America. The point here is that much of what Nazi Germany accomplished in gaining power was related to their propaganda and their propaganda took full advantage of broadcasting. Goebbels noted in his diaries that he was able to use propaganda to build the Hitler Fuhrer mythology (Manvell \& Fraenkel, 2010). The Nazis believed that people can be convinced of truths best when the messages are very simple and highly repeated. It took some time for the USG to realize how effective German propaganda was with both internal (domestic) and external audiences. Hitler himself believed that one major reason for Germany losing World War I was the effectiveness of American propa- ganda. Seven organizations were used by the USG to fight Nazi propaganda and to use communication to help the war against Germany and its fascist allies. Psychological warfare, information services, and propaganda were all used to combat Nazi claims and credibility, as well as to degrade the morale of those who supported Hitler. The three most important organizations were the OWI, the OSS and the Army. The latter two were heavily involved in covert communication projects.

The aggressive propaganda/PD of the Soviet Union and its leader Josef Stalin, convinced American leaders that their nation needed a strong voice against the messages of the Soviets. While the National Security Act of 1947 created the DOD and the CIA, it did not create a central information office like the CPI or the OWI. However, the CIA was given authority to conduct covert psychological operations to counteract the actions of the Soviets. In 1948, the Smith-Mundt Act gave legal authority for overt information campaigns. The law called for official dissemination of information about America, its population, and its policies. One of the stated goals of this law was to enhance understanding among nations (Kennedy \& Lucas, 2005). The VOA was run from within the State Department at this time. All of this was done to support U.S. foreign policy which included the Truman Doctrine, and the expansion of American influence.

Like the CPI of World War I and the OWI in World War II, the United States Information Agency (USIA) was established to persuade people in other nations that the United States national interests and national security policies should be supported. The USIA was established in 1953 and was terminated in 1999, when its functions were returned to the DOS. Since 1999, PD and United States SC have been loosely coordinated and subject to competing paradigms and definitions of terms. Still, the history above shows that the United States needs strategic influence and countercommunication at the same time that it favors building cultural relations through various forms of diplomacy. There are few options when so many communication spheres of influence include messages attacking the U.S. and its policies.

\section{International Broadcasting and Public Diplomacy}

Writing in 1937, Silas Bent noted that messages sent to other nations from the United States and messages sent to America from other nations are both nationalistic and conducive "of better international understanding" (p. 117). He also referred to radio music programs furthering good will. Additionally, he observed that sport coverage of events like the English Derby and the Davis Cup finals "help to give to the world a sense of common possession, if not of solidarity" (Bent, 1937, p. 119). It appears that international broadcasting would be a preferred tool of publicity for both fas- 
cists like Hitler and Stalin and anti-fascists like Franklin Roosevelt. Ideological operations became part of war mobilization. The first major technology used was the one used by America's allies and enemies. This was radio and it became the main tool of the Voice of America. The VOA started on February 24, 1942 and its first words were "We shall speak to you about America and the war-the news may be good or bad-we shall tell you the truth" (Snow, 2014, p. 8). The end of World War II brought declining interest in ideological warfare, but it increased again with the emergence of the Cold War.

Before the formation of the USIA, information and ideological operations, both overt and covert, were conducted by the military and the DOS. The latter's Policy Planning Staff established efforts to roll back aggression by the Soviets in Eastern Europe (Dizard, 2004). The CIA, which was the successor to the OSS, secretly ran Radio Free Europe and Radio Liberty. Radio Free Europe was on the air in 1951 (Kennedy \& Lucas, 2005). The content of these radio stations was consistent with the DOS Policy Planning Staff goals for challenging the Soviets. At the time of the USIA formation, public diplomacy and information operations were influenced or conducted by the National Security Council, the $\mathrm{CIA}$, the DOS, the DOD, and the White House.

The impetus for creating the USIA was closely related to USG objectives in the Cold War. The goals of the agency were to explain the policies of the United States, counter adversary propaganda, and to help others understand American culture (Arndt, 2005). Cultural affairs officers, who believed that the State Department had started with the right focus on cultural diplomacy in 1938, were disappointed with these goals. They believed that the USIA did not concentrate enough on mutual understanding of other populations along with various types of partnerships (Arndt, 2005).

The 1999 demise of the USIA meant that public diplomacy would be steered officially by the DOS. Two components of the USIA, International Information Programs and the Educational and Cultural Affairs bureau, were now to be run by the undersecretary for Public Diplomacy and Public Affairs (Lord, 2006). A third part of the USIA, the Office of Media Research and Analysis became part of the State Department's Intelligence and Research Bureau (Lord, 2006).

American leaders have supported large-scale ideological operations in times of war such as the two world wars and the Cold War. After the Cold War and collapse of the USSR, it was assumed that the USIA was less necessary. Since then, however, the Cold War has been replaced by the present war on insurgencies and terrorists. While there was support for centralized PD during the two world wars and the Cold War, some observers note that the USG was behind our allies in the commitment to ideological operations (Doorey, 2009). During the Cold War, the VOA, which existed before and after the USIA, reached about $80 \%$ if the Eastern
European populations. In recent times, without the USIA, the VOA has reached only a small percentage of people in the Middle East (Doorey, 2009). Official VOA figures indicate that the VOA reaches $80 \%$ of the total American international media audience. ${ }^{7}$ From Washington, D.C., the VOA produces more than 70 TV shows and 200 radio programs. VOA services include websites and social media sites.

While there are tensions between SC, PD, and ideological operations between one side of America's international influence and cultural diplomacy and partnerships on the other side, history shows the division is not necessary. Hard power and soft power sometimes work together while soft power can work on its own or in tandem with hard power (Nye, 2004). Cultural diplomacy is preferable to 10 but is longer-term and does not address rapid-attack communication from adversaries. The USIA was able to combine soft and hard communication and its effectiveness in the Cold War still presents a model, albeit not without problems, for a unified approach to USG international influence. Unlike the CPI, the USIA was not viewed negatively by the public or Congress in any major sense. Its demise appears to be more related to the USG wanting a more active role for the DOS in PD and some politicians seeking to cut budget costs during another period of peace (Arndt, 2005; Dizard, 2004). The agency had successfully countered Soviet propaganda during the Cold War with VOA, Radio Marti, and Radio Liberty. It also continued cultural diplomacy such as like cultural exchanges and scholarships (Paul, 2011).

\section{Controversies Regarding International Broadcasting}

While the international broadcasting component of national influence began with radio, it has extended from radio into television, the Internet, and social media today. Historically, international broadcasting has been defined as state-sponsored news, information, and entertainment directed to the populations of other nations (Price et al., 2008). It was once unabashedly associated with necessary propaganda and is now affiliated with PD (Price et al., 2008). One problem with defining it has been the changing technological nature of international broadcasting, particularly in light of the fact that target audiences are no longer necessarily limited to nation-state boundaries. More importantly, there are continuing questions about how objective or stateserving international broadcasting services need to be. There is also the observation that new media and social media diminish the one-way flow that typified radio transmissions.

The questions of objectivity involve issues of both intentional and unintentional support of state themes and positions on foreign affairs (Price et al., 2008).

\footnotetext{
${ }^{7}$ http://www.bbg.gov/broadcasters/voa
} 
From the early days of shortwave radio to the social media networking of today, international broadcasting has had to balance two competing commitments-one to objectivity in order to maintain credibility, and the other to serving the national security interest of the government it serves (Price et al., 2008). Strong critics of broadcasting for PD argue that the sources are always finding themselves in the role as "missionaries of ideological and cultural hegemony" (Price et al., 2008, p. 154). Others may note that what the BBG and State Department subscribe to in terms of objectivity does not have to be applied by the DOD or intelligence community messaging. Rhetoric about truth telling must therefore be qualified as applied to particular areas of government strategic communication. Traditional state broadcasting and clandestine information transmission are not the same thing (Price et al., 2008).

Some criticisms of international broadcasting assert that actual effects are difficult to identify. The BBG measures total audience size of broadcasts, website visits, program quality ratings by audiences, audience perceptions of program credibility, and audience reach (Weed, 2014). Audience reach is the percentage of audience respondents who watch or listen weekly. Another variable measured is the percentage of audience respondents who say that certain programs have helped them understand current events more (Weed, 2014). Generally, these data are very positive. For example, in 2013, VOA had $100 \%$ of its audience rating its quality high, $89 \%$ on credibility, and $90 \%$ on understanding (Weed, 2014). Still, some critics say that international broadcasting has not moved the needle in regard to advancing U.S. foreign policies and promoting democracy (Weed, 2014). Perhaps some of this disappointment results from an incomplete understanding of what international broadcasting is legally required to do-present objective news in a manner consistent with American foreign policy.

In 2014, a report on international broadcasting for the USG was released by the United States Advisory Commission on Public Diplomacy. In that report, Nicholas Cull wrote an executive summary making the following observations. What has sometimes been viewed as unmeasurable it now subjected to multiple forms of tracking and analytics. Despite the fact that having more data about audience attitudes and behavior can help adjust programming, there is still the problem of political leaders consulting with public diplomats as they formulate policies (Cull, 2014). The commission report reminds us that international broadcasting is intended to inform rather than persuade. At the same time, it must align with USG foreign policies and work against political extremism.

As a complete reading of the national influence literature reveals, there are many domains of international broadcasting, some of which is done by the BBG. The BBG oversees only civilian messages and network- ing while the DOD has its own system of broadcasting. Within the BBG family of stations and websites, there are variations of purposes and strategies. Additionally, the intelligence community has covert broadcasting operations, which are obviously difficult to locate and describe.

Historian Ron Robin (2005) argues that "Contemporary public diplomacy appears trapped in a time warp... its architects are creatures of cold war triumphalism" (p. 347). Robin and others declare that American PD has replaced the monster of Communism with a new dragon to slay-terrorism. These critics say that such binary thinking neglects the complexities of identities and changes that should be studied. This line of criticism says that existing approaches to national influence and international broadcasting gloss over the complexities involved in adversarial contexts. Robin (2005) charges that there is no yearning by Muslim populations to be liberated by Americans, but that is what Americans portray in their PD. Robin (2005) says a major problem with the use of American international broadcasting is the assumption by the sources that the receivers lack information, when in fact, they are inundated with various forms of information and communication. In other words, animosity toward the U.S. may result more from negative information rather than a lack of information.

Some critics say that "U.S. public diplomacy has undergone intensive reorganization and retooling as it takes on a more prominent propaganda role" (Kennedy \& Lucas, 2005, p. 309). These kinds of criticisms imply that new forms of national influence are no different than those used in WWII and the Cold War, albeit taking new forms and using new technologies. There appears to be some suspicion of new terminology like "new public diplomacy" in such critiques. Such arguments go far as to say that the new public diplomacy, like the old, is not only serving national security, but also imperium building (Kennedy \& Lucas, 2005).

In fact, despite the propaganda roots of national influence, it is not necessary for national influence or strategic influence to serve the needs of empire building, hegemony, or political warfare. This makes charges of "cultural imperialism" interesting, but inconclusive. Certainly, information warfare, information operations, and propaganda can be part of a nationalistic strategic influence, but other, perhaps larger, parts can include cultural networking, networking of policies, and collaborative policy directions. There is no realistic denial of national influence (SC, PD) serving the interests of the state, but the interests of the state can move from unipolar to multipolar, and unilateral to multilateral. With increasing interdependence of economic, political, and military systems, there is good reason to expect more attention to the potential of network diplomacy. The question here is how international broadcasting, born in the old paradigm, can contribute to the new one. 
Searching for something sinister in national influence campaigns that are used in many ways at various levels of transparency may be more interesting than productive. It is true that the State Department's George Kennan had a plan in 1948 called "organized political warfare," but we must ask why we should expect him to not have such a plan. ${ }^{8}$

There is critical scholarship in the social sciences that views national influence as contemporary propaganda, regardless of new terminology and new approaches to international communication. One argument is against the Obama administration's focus on global engagement. It accuses the USG of using engagement in the same way used in corporate public relations and marketing. The accusation is that this produces contrived dialogue rather than genuine dialogue (Comor \& Bean, 2012). Additionally, the use of Public Diplomacy 2.0 is charged with being a means to facilitate and enlarge a PD approach that is not workable. Comor and Bean (2012) suggest that the new public relations "two-way symmetrical model" is simply doing public relations for the public relations profession. They also argue that the co-creational arguments made by new PD scholars are selling something no more effective than the Charlotte Beers marketing approach to extremist terrorism. Moreover, they argue that just as the theory of symmetrical relationships between companies and consumers has not been proven to work, the USG has not explained how it can begin to create such relationships (Comor \& Bean, 2012). As for the claims about individual empowerment through Web 2.0 technologies, some say these are more related to Wired magazine articles than empirical evidence (Comor \& Bean, 2012). ${ }^{9}$

In the history of PD provided by Michael Schneider (2015), it appears that there is not only the story about America that gets told, but also the story about PD. One interesting chapter of the PD story is the attempt by the USG after 9/11, to gain more worldwide support for what Americans called the "war on terror." The goals were fairly clear, but the communication strategies were not. Between 2001 and 2013, there were 7 different undersecretaries of Public Diplomacy and Public Affairs at the State Department (Schneider, 2015). The point of this observation is simply that consistent leadership in national influence is difficult when the leaders keep leaving. None of the seven stayed on for more than two years. The last two undersecretaries appeared to be more credentialed in journalism than in

\footnotetext{
${ }^{8}$ http://academic.brooklyn.cuny.edu/history/johnson/65ciafou nding3.htm

9 While these scholars have made points worthy of deliberation, they have not proven that engagement online or offline cannot be improved in ways that free the new approach from the old advertising paradigm.
}

international relations. ${ }^{10}$ Some of the undersecretaries advocated new listening, better relationship building, and newer communication technology efforts (Schneider, 2015). In response to slow and inadequate civilian USG responses to terrorism communication, the DOD developed its own forms of SC influence. In time, the Obama administration developed means to bring together concepts used by both the DOS and the DOD for national influence, particularly against terrorism (Schneider, 2015). Two "whole of government" approaches supported by the White House included the Center for Counter-terrorism Communications (CSCC) and the National Counterterrorism Center (Schneider, 2015, p. 20). The Obama administration makes it clear that its attempt to use SC and global engagement includes efforts to "engage audiences on positive terms," but also "discrediting, denigrating, and delegitimizing al-Qa'ida and violent extremist ideology" (White House, 2010, p. 6).

\section{The New Public Diplomacy}

The older versions of public diplomacy appear to be more like propaganda than the more recent versions. The newer arguments about public diplomacy advocate more interactive approaches to communication with other nations and populations. While the new media (Internet-based) have not replaced the old media (preWorld Wide Web), there is an important blurring of content production and content consumption in today's media ecology. New media present vast amounts of channels and networking platforms for locating, producing, and disseminating various forms of communication content. While the State Department has attempted to use social media for the constant goals of strategic influence, there is scant evidence of success in this area. Worse yet, there are several examples of DOS disasters in design including the recent video about running to ISIS rather than walking. ${ }^{11}$ Perhaps letting go of a dominance paradigm for foreign affairs now still held by the United States government (despite academic claims to the contrary), could make more effective uses of new and social media possible. Clearly, the goals of security and global positioning will direct the influence of activities of the government, despite what labels are given to them.

Many lessons have been learned from the older

${ }^{10}$ Richard Stengel, current head, for example is a former editor of Time magazine and journalism professor. (http:// www.state.gov/r/pa/ei/biog/221669.htm). The previous head was Tara D. Sonenshine, whose background was in strategic communication for organizations, foreign policy, and media production (http://www.state.gov/r/pa/prs/ps/2012/04/18745 4.htm). She only stayed on for two years.

11 This video is attempted DOS information operations: http://www.military.com/daily-news/2014/09/09/statedepartment-enters-propaganda-war-with-isis.html 
days of PD that guide what is now formulated as new PD. One strong lesson is that PD cannot make up for bad policies and PD does not work if it contradicts foreign policies or military operations (Melissen, 2007). New PD is less propagandistic than older PD and requires news skills than those found in traditional PD (Melissen, 2007). It is also focused more on engagement with other cultures. This engagement includes links with civil society organizations and publics through non-governmental channels (Melissen, 2007). Jan Melissen (2007) cautions that too much coordination between policies and PD can create negative impressions. To distance itself as much as possible from propaganda, new PD seeks dialogue and two-way communication as opposed to the one-way persuasion efforts of propaganda (Melissen, 2007). Some of the new PD is related to the cultural relations effort going back to the establishment of the cultural relations office in the DOS in 1938. Efforts at cultural relations stress engagement with other populations in various cultural partnerships, not in the one-way manner of Nelson Rockefeller's efforts in Latin America, but in the sense of long-term trust building (Arndt, 2005; Melissen, 2007). Thus, new PD can conduct traditional persuasion efforts while adding more endeavors for relationship building (Melissen, 2007).

New PD brings a stronger focus not only on cultural relations and trust building, but also networking of interests, cultures, and diplomacy itself. Hierarchical information flow (marketing, propaganda, advertising, public relations) models of PD are challenged today by new PD models that stress policy formation networking and collaborative policy making over unilateral policies sold by good selling techniques (Hocking, 2007). While new PD is less one-way informational than new PD, which is more dialogic and cooperative, we have to question the equation of the old PD with broadcasting. Pamment (2013), for example, states that new PD 'represents a break from the 'broadcasting' models and takes advantage of social media to establish twoway engagement with the public" (p. 3). It is important to recognize that international broadcasting, when linked with websites, social media, and other platforms may become more like the converged media we see with other channels.

While our history of international broadcasting necessarily stressed radio, it is very important to note that today's international broadcasting involves much more than radio and TV, as the Internet has provided many new channels over time. For example, the USG's International Information Programs Bureau (IIP) today makes efforts with numerous websites designed to attract young people. These sites along with Facebook, mobile phone apps and other new media appeals, attempts to disseminate important PD information. It also employs various forms of analytics to track what messages are having specific effects with particular types of audience members (Schneider, 2015). The IIP has distributed over 300,000 e-books to other nations (Schneider, 2015). Despite the new media, however, most people in the world still get their information about the world from radio and TV (Schneider, 2015). Such observations make it clear that the USG is updating its technological tools for international broadcasting. The question now is whether or not the messages and the communication strategies are also being updated.

Today's shifts in using international broadcasting for PD appear to stress more two-way communication between PD senders and receivers, and more networking attention which can bring into focus non-state actors who can be influential with various audiences (Powers \& Samuel-Azran, 2015). After 9/11, USG international broadcasting increased its pro-America news. USG networks like Al Hurra (satellite TV) have to compete with the political news of Arab networks such as Al Jazeera and Al-Arabiya (financed by Saudi Arabia), and have had small effects on attitudes about the U.S. (Powers \& Samuel-Azran, 2015).

According to Maloney (2015), the use of social media for PD displays its limitations. Maloney argues that the Iranian situation illustrates the possible overreliance on PD to the exclusion of traditional diplomacy. She argues that the recent negotiations between Iran and America are due to traditional diplomacy, not public diplomacy or digital public diplomacy. With advances in international broadcasting capabilities into Iran, the government there responds with new measures to suppress expansion and effects. Maloney suggests that the strong concern about international broadcasting reflects the effect that international broadcasting is having on Iranians. In 2001, the Iranian government ordered the filtering of all websites that are deemed anti-government or anti-Islam. In 2003, harsher measures were taken including arresting journalists and bloggers. Weed (2014) argues that there are disagreements today about how this form of PD works best in an age of digital media and networking and also the exact ways it contributes to democracy and US foreign policy objectives.

While it is tempting to say that the old PD is faded or fading, studies show that new PD may not be moving as fast in practice as it is in academic discourse (Pamment, 2013). This lag may parallel the disconnect between how scholars talk about social media and democracy and what is actually found in empirical data (Hacker \& van Dijk, 2000). One scholar argues "Record a few minutes of video on your phone, post it on YouTube, and millions can watch whatever you have decided is newsworthy" (Seib, 2012, p. 9). The problem with this statement is the fact that posting a video on YouTube might get a dozen views or a million views depending on factors that go well beyond simply posting content. With social media, there is always potential for progress, but it is wise to keep a realistic view of 
what changes are actually occurring. One interesting point of separation between older PD and newer PD is that the latter is more likely to build on narrative in an inductive manner while the former is more likely to use grand national narratives that are distributed (Pamment, 2013). Research in 10, done in the battlespace of open confrontations, shows that grand narratives are not likely to work in today's world of asymmetric conflicts (Perna, 2009).

Having reviewed some important aspects of the history of American national influence, how international broadcasting attempts to turn away from old diplomacy and toward new public diplomacy, how strategic influence and global engagement should be used together for national goals, and some strong criticisms and of broadcasting and public diplomacy, we now move into a discussion of how international broadcasting can be part of an integration of mass communication with social media and digital communication.

\section{Building a Unified Model of Strategic Influence and Global Engagement}

According to Bruce Gregory (2008), PD and SC are essentially the same thing-governmental persuasion. However, Gregory wants to separate PD and SC from information operations (IO). Like Joseph Nye, he combines the concepts of coercion, persuasion, and attraction into the concept of "smart power." Gregory says that PD and SC are open persuasion and IO is covert or hidden persuasion. ${ }^{12}$ Gregory also makes the important

12 Strategic influence can be overt or covert and can include in- observation that the DOS and the DOD are not the only stakeholders in PD and SC. There are also private interests and civil society organizations involved in their own ways of doing PD. There is an alternative to using IO which is basically in the arsenal of communication weaponry used more by the military and the intelligence community than by other USG sectors. ${ }^{13}$ That alternative is strategic influence as we have been discussing it.

Because there is a full spectrum of threats to national security, it is necessary to develop a full spectrum of security and communication strategies for all of those threats. This is true for both times of peace as well as times of wars and violent conflicts. In Figure 1, the argument is visually depicted as global engagement (cultural relations, partnerships) combining what are often thought of as competitive and exclusive aspects of strategic influence.

The main arguments of this perspective begin with the claim that separations, or stovepipes between SC done by the military, $I O$ done by the military and the IC, PD done by the diplomacy community, and traditional diplomacy are useful for firewalling tactics. However, they are not useful for the integration of necessary goals of communication that best serves national security concerns.

formation operations. How secretive $I O$ is in practice is subject to debate.

13 Technically, military or intelligence community 10 can also include violent actions such as cyber-attacks, electronic warfare (EW) and kinetic attacks on communication or information infrastructures.

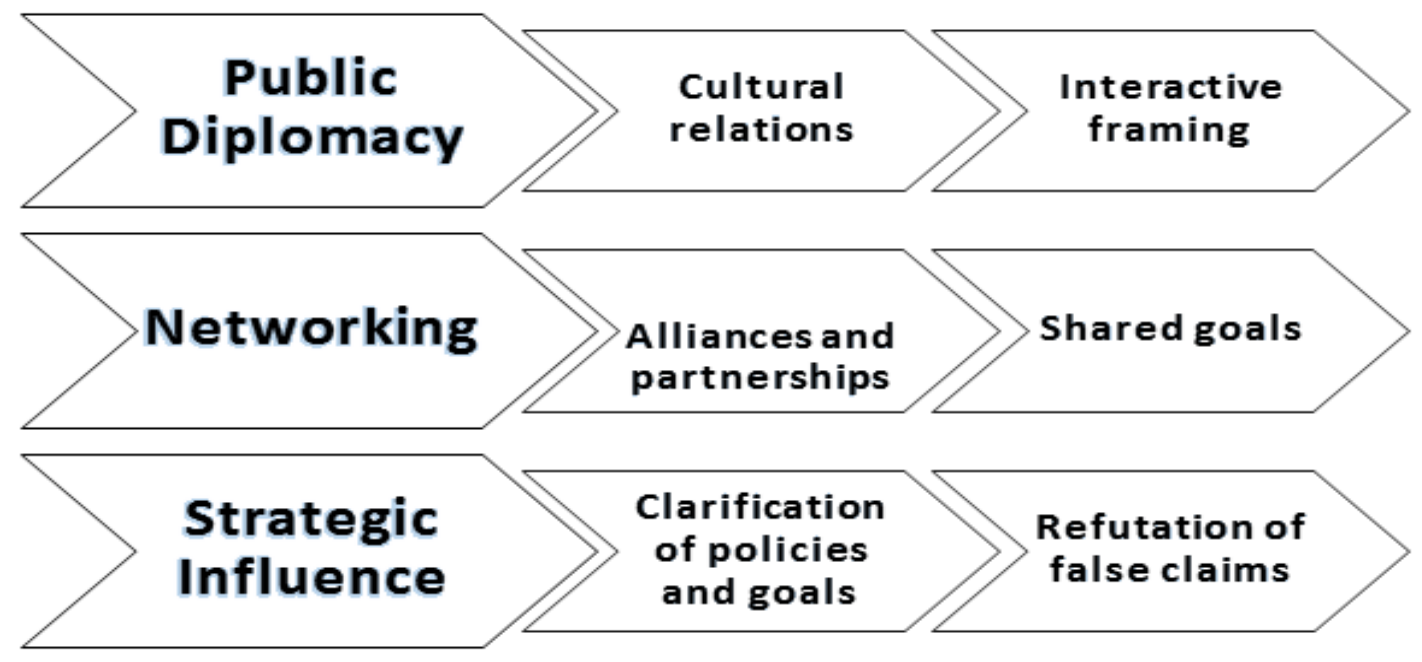

Figure 1. Parallel paths of strategic influence and global engagement. 


\subsection{Cultural Networking and Global Engagement}

Zaharna (2010) maps out a spectrum of national influence that might be useful moving forward in coming years. The older focus on strategic information and influence can work with the newer focus on building relationships in her model. The relational side of a fullspectrum framework focuses on the construction of social structures to advance political objectives. Zaharna's (2010) new vision is based on the argument that SC and PD must include both information and relational perspectives. In fact, she says that the two should be integrated. She uses interpersonal communication as a useful analogy in her view, for recognizing how both relational and informational aspects of communication are essential. Rather than relying so much on battles for hearts and minds, her approach focuses more on building cultural bridges.

After 9/11, Zaharna (2010) notes that the U.S. mainly used transmission (mass communication) models of PD to attempt to generate soft power. However, she argues that connection, relationship-building, and networking approaches, as used by NGOs, appear to be more effective. The U.S. was not generating soft power as much as it was trying to persuade people about it ("wielding soft power"). The older approach stresses message content over message exchange. This transmission model of soft power is essentially a propaganda model as the messages are one-sided, carefully controlled, and designed for changing receivers, not senders. Essentially, you are attempting to get the message receivers to do want what you, the message sender, desire. The goal is about more compliance than collaboration.

Network diplomacy, long advocated by Zaharna (2010), is an alternative to propaganda-based national influence. Networking persuasion or influence builds on the recurrent finding in communication research that the best avenues of persuasion are interpersonal networks. Viewing strategic influence in terms of systems helps us to recognize that various channels of communication have specific functions and also that these functions can change the activity situation of an individual. Thus, a person who normally attends political news with Internet and TV sources, may become a radio news listener during times of driving a car. Network weavers are people in social networks who create network links with others. (Zaharna, 2010). A very important part of influence networks are called hubs. Hubs are people in social networks that have high centrality in the networks-people who through messages pass to get to other members of the network. Many political networks that receive or diffuse PD message are all-channel networks in which there are many hubs and messages are not easily diffused in linear steps or flows. Leadership is shared in these kinds of networks.

Zaharna (2010) notes that narratives are important to these networks because the storytelling helps to produce shared group and network identity. Both strong ties (people you know well and trust highly) and weak ties (people you know but are not close to) are important to network influence and how PD is affected by networks of reception, interpretation, and dissemination. Diversity of network members help bring new ideas and perspectives into social interaction. Members who link diverse groups are known as "cultural bridges." Master narratives are used to frame problems and solutions for networks. Stories are local and master narratives are global. Stories are used to recruit people into networks. Networking approaches conducted with stories and narratives are not the same as mass communication or propaganda model of "telling our story" or narrative. While narratives in the older Information Model are used to persuade and sell and stories are shaped to be marketed, the narratives in the Networking Model are shaped by both senders and receivers.

\subsection{New Media Networking and National Influence}

Societies with communication that was mainly organized with mass media were known as mass societies or information societies. Societies with communication that is organized mainly with Internet and wireless networking are known as network societies (van Dijk, 2012). Counter-power is exercised in the network society by fighting to change the programs of specific networks and by the effort to disrupt the switches that reflect dominant interests and replace them with alternative switches between networks. Actors are humans, but humans are organized in networks. Human networks act in networks via the programming and switching of organizational networks. In the network society, power and counter-power aim fundamentally at influencing the neural networks in the human mind by using mass communication networks and mass self-communication networks (Castells, 2009, 2010). It is important to note that international broadcasting will have to become integrated with the networks we are describing to optimizes its relevance for national influence.

Castells (2011) describes a new global public sphere for public diplomacy that results from increasing globalization and interconnections with new communication technologies. This argument is idealistic and interesting, but is not as useful as his basic principles of network theory and power. In view of these principles, even smaller nations can join in international debates more than ever before and also increase their influence on how international crises are framed. While we do not agree with his claim that public diplomacy is "diplomacy of the public, not of the government" (Castells, 2011, p. 78), we see merit in Castells' arguments about a possible global sphere of networked citizens of the world having 
the ability to deliberate and debate world issues in far easier ways that ever before. While the new electronic spheres of deliberation made possible with emerging network technologies may allow more networking of government, non-government organizations, civil society, and citizens alone, there are opportunities for PD to be used in these spheres for engagement and influence. If online global spaces for people from different cultures are able to facilitate the deliberation of political issues in a kind of online civil society, there may be potential for what Castells (2011) refers to as "the movement of public opinion, made up turbulences of information in a diversified media system" (p. 86). Castells' view of PD is that of networked communication, cultural engagement, and shared meanings.

Castells' work shows that new media networking allows new social spaces where power can be shaped (2007). Castells (2007) describes a trend where "mass media and horizontal communication networks are converging" (p. 238). Thinking shapes norms and social interaction in the new online spaces affect thinking. As Castells (2007) explains, "the battle of the human mind is largely played out in the processes of communication" (p. 239). This is also true of power relations. Perhaps it is also true for the effects of national influence. In the age of mass communication, theories like the two-step flow of communication could explain message diffusion and some aspects of network influence. Today, however in the age of networking and new media, multiple-step theories of communication are required to explain where message are diffused and how networks of influence are affected by SC and PD. We also have to look at media ecologies rather than simple single-media descriptions of effects. This is because people live in multimedia environments and receive from multiple channels and use multiple channels to create their own content as well.

Social media cannot be reduced to one platform of social networking in any attempt to explain how networking operates with new media. Thus, Twitter studies will not say much about Facebook and vice versa and research on one of these will be limited to just one part of social media. This is why it is important to study more than networks of people and to also examine networks of new media and various usages of them dynamically affect various actions of users. While message receivers are always involved in producing meanings for what they perceive in communication, social media allow receivers an increasing amount of control over personal interpretations as they process political content. If this becomes more empirically verifiable, we can suggest that social media are part of a communication ecology that affords more control or influence over how political situations are defined and framed (Altheide, 1995). When we adopt the concept of media ecology or perhaps new media ecology we are led to step past old notions of single users with single tech- nologies accomplishing significant political work.

Social media involve connection technologies used via the Internet for purposes of social interaction with other users. Social networking sites (SNS) include Facebook, Twitter, LinkedIn, Reddit, YouTube, etc. Each one has its own features and usage affordances. Each can be linked to all of the others in whatever constellation determined by users one by one. Van Dijck and Poell (2013) refer to this as an "expansive ecosystem of connective media" (p. 5). These researchers are careful to avoid falling into the trap of explaining social media by their affordances, either individually or in interoperable linkages. Other researchers observe ways that international broadcasting can be integrated with social media. Tufan (2014), notes that social media and Internet usage provide opportunities for interactivity among users that are not found in typical mass media environments. However, broadcasting sources can easily link to social media platforms that connection spheres of user interactivity to spheres of typical audience reception. Accordingly, "new program formats have been developed that use these platforms to enable listeners and viewers to directly and easily interact with running radio or television programs" (Tufan, 2014, p. 95).

Communication research has long documented the active nature of audiences (Castells, 2007). At the same time, we also know that commercial and political interests affect just how free various new forms of communication actually are in terms of political content. With new media, it is possible to have what Castells (2007) labels "mass self-communication." The key here is expanding horizontal networks of communication that connect global to local messages. Castells describes mass self-communication as a network created by individuals in their personal configurations of Internet, Web, cell phone, and other new media. We suspect we should add all possible media including both old and new, and also offline interpersonal connections. Following the communication power theory of Castells, we can see that power and influence are increasingly related to networks of meaning that are formed in new geometries of multiple communication channels.

Applying Castells theory to international broadcasting cases of message challenges by adversarial groups or nations or state governments, autonomous horizontal networks linked to more global networks can provide a more useful model that old-fashioned point-toreceiver models. This is because the new media/social networks can challenge the information received from governments and adversarial organization. Broadcast media, as used by international broadcasting, should become less one-directional while expanding horizontal networks that converge old media channels and new media platforms (Castells, 2007).

An uncritical view of "Public Diplomacy 2.0" or one that is theory-free can generate beliefs in an exaggerated role for social media and digital communication in 
regard to national influence. While much of public diplomacy is offline, online components of influence join in systems of information and social interaction that make the importance of new media fairly clear (Gregory, 2014). As Bruce Gregory (2014) notes, the revolt of the "Arab Spring" involved much more than social media like Facebook. Other facts like corruption, scarcities, TV, military actions, and street activities were also part of the total picture. A great deal of research has yet to be done to sufficiently clarify how the various channels of social media form systems of information flow and influence. The same is true for how the old media and new media work together. As Gregory (2014) argues, "It is easy to argue the importance of technologies in the abstract; it is harder to refine the operational implications" (p. 13).

A system of national influence includes all forms of SC and PD. This can be seen in Figure 2. The propositions used in building this model begin with the need to end the stove-piping of various forms of national influence without making them all sound the same. It also attempts to bring together what has been conceptually separated since the end of the USIA, that is, the separation of strategic influence from public diplomacy. Another proposition concerns that roles of smart diplomacy in determining what blends of strategic influence and global engagement are most likely to be effective in particular situations. A fourth proposition links the various forms of diplomacy, ranging from softpower oriented forms like cultural diplomacy to more hard-power forms like coercive diplomacy, into the practice of smart diplomacy.

The propositions in the model of national power and influence shown above are grounded in the assumption that strategic influence (strategic communication, public diplomacy) can be logically paired with the goals of global engagement. International broadcasting is assumed to have roles to play in every part of the model. We stress engagement because it appears that enhanced global engagement is the lodestar for much of the argumentation done today about a new PD and the need for network diplomacy. We believe engagement, when genuine, is like the traditional arguments about the "last three miles" of diplomacy.

The reasoning for this model of power and influence is somewhat consistent with the integrated model for public diplomacy argued by Guy Golan. The Golan model has three levels of USG influence domains. The first, called mediated public diplomacy, involves strategic framing and competition over framing. Golan (2015) notes that "Governments must recognize that public diplomacy does not occur in a vacuum" (p. 418). As noted earlier, despite enormous penetration of new media, most people still get a great deal of political information from the old media (Golan, 2015). Ironically, international broadcasting may take on new important roles at the time that they are dismissed by some as Cold War relics. The three domains described by Golan (2015) are mediated public diplomacy, nation branding or image management, and relational or network management. While his model does not approach the totality of USG strategic communication/national influence needs, it does provide a useful model for integrating the PC side of American governmental persuasion. It also provides a useful context for some of the aspects of international broadcasting which need improving.

Golan's (2015) concept of mediated public diplomacy refers to strategic framing. Strategic framing is akin to framing done by political campaigns and involves a competition for agenda setting at both the first-order (setting news and public agendas) and second-order levels (salience, interpretations). Therefore, Golan argues that mass media and public relations theories can be applied in this area of PD. Robert Entman (2008) argues that mediated public diplomacy consists of strong USG attempts, led by the White House to control the framing of American policies. Thus, we can see that international broadcasting has a sustained role in USG frame setting and frame competition.
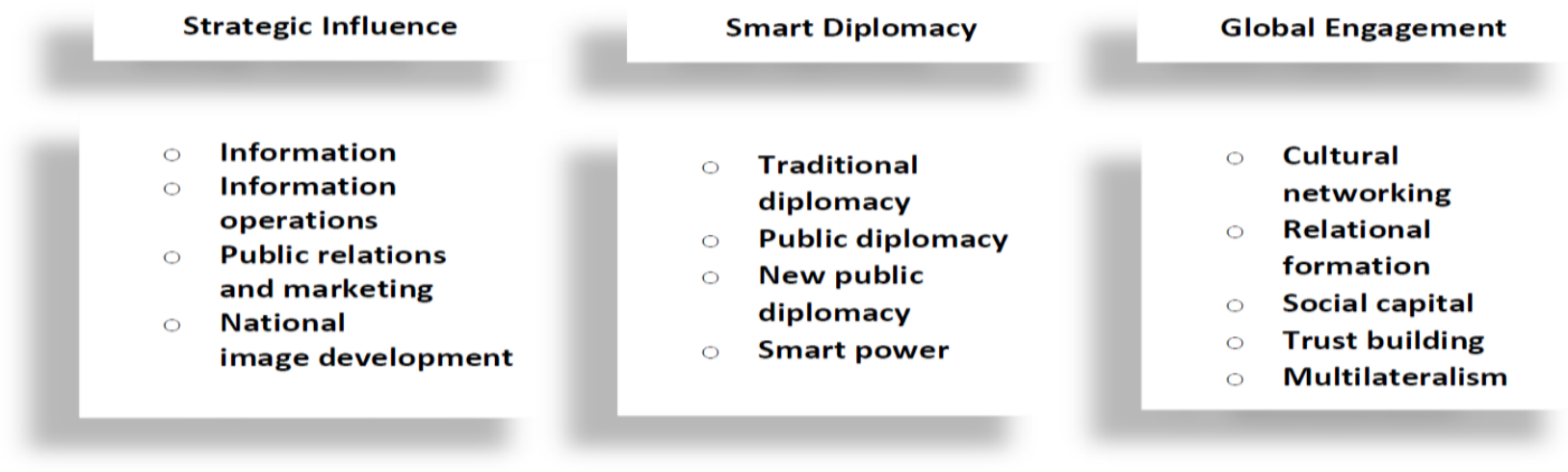

Figure 2. Model of strategic influence and global engagement. 
Golan's (2015) second PD domain is nation building and reputation management. The problem with this domain is that it can rely too much on persuasion strategies imported from business-marketing, advertising, etc. On the other hand, branding can work if media framing has already successfully framed a nation is positive ways (Golan, 2015). More important, perhaps, is Golan's (2015) third domain, relationship formation and management. This third view assumes that increasing positive long-term relationships between Americans and others in the world can improve America's image as well as increase the nation's soft power.

\subsection{Culture and International Engagement}

Cull (2013) observes that engagement with other cultures to the extent that policies involving them, are related to effective listening and feedback processes. Foreign policy is adjusted to foreign opinion, not simply thrust at it. Cull (2013) argues that cultural exchange where both sides of the exchanges learn about each other. He also makes the case that broadcasting that is objective news lowers filtering. Objectivity is perceived as more ethical than propaganda and ethical communication is generally more persuasive. On the other hand, he acknowledges that a nation has to respond to the types of strategic communication used by its adversaries. When the USSR was found to be using intense psychological warfare against the U.S., the latter decided to do the same.

Military analysts have found that America has trouble communicating with other nations and cultures because analysis of existing "background conversations" present in the cultural contexts is sparse. With poor analysis of cultural terrains and contexts, no amount of PD modeling will have significant effect on populations who resent America policies. Background conversations are cultural backdrops which add contexts for producing and understating explicit conversations (Perna, 2009). For example, American soldiers saw no harm in placing an American flag over the head on a statue of Saddam Hussein they helped to pull down. To the Iraqis, the action symbolized what was in their background conversations, that is, that Americans are conquerors (Perna, 2009). For the kinds of political changes that America seeks with using SC and PD, it is necessary to use communication platforms like international broadcasting linked to new media, social me$\mathrm{dia}$, and interpersonal networks to challenge the background conversations and replace bad ones with good ones when possible. It is easy for people with similar cultures and poetics to use social media and new media networking (Seib, 2007). But a more important challenge for national influence and international broadcasting is how you get people with dissimilar backgrounds to network.

\subsection{Strategic Influence}

While cultural relations and networks are very important to new public diplomacy, it is also critical to remember that there are adversaries also putting out their own SC and PD messages. If we look at Iran, for example, it is inadequate and non-explanatory to simpIy list channels that send signals into that nation. Instead, we have to study the SC and PD done by the Iranian government as contextual background for where USG influence is likely to have significant effects. As America has its arsenal of international broadcasting channels, the Iranian government has its Islamic Republic of Iran Broadcasting (IRIB) system (Tiedeman, 2005). Iran has no equivalent of Smith-Mundt Act restrictions on propagandizing its domestic audience. The IRIB employs 24 languages for its messages (Tiedeman, 2005). While some of its broadcasting aims to familiarize other nations with Iran's history and culture, its Voice of Justice programming is focused on criticizing American interventionist policies (Tiedeman, 2005).

In over three decades, Iran and the U.S. did not have formal diplomatic relations. Despite recent negotiations and a recent famous deal over Iranian nuclear programs, both national governments remain suspicious of each other. In recent years, however, the DOS has developed some online strategies for increasing dialogue and trust-building (Fialho \& Wallin, 2013). The online tools are used along with other forms of PD and also traditional diplomacy. In 2011, the DOS launched the Virtual Embassy Tehran. The purpose for this Web hub is to increase communication between the USG and Iranian citizens (Fialho \& Wallin, 2013). It has the dual roles of promoting mutual understanding and refuting misinformation. One goal is to shape the views of Iranian youths (Fialho \& Wallin, 2013). This site provides what Fialho and Wallin (2013) call "virtual engagement" (p. 3). About $50 \%$ of Iranians use the Internet today, but the Virtual Embassy Tehran website was blocked by the Iranian government soon after it opened (Fialho \& Wallin, 2013). However, despite the fact that most of the site hits are coming from outside of Iran, the DOS believes that Iranians view the site using proxy servers (Fialho \& Wallin, 2013). In additional to the virtual embassy, the DOS has a Farsi Facebook page, a Twitter account, Google+, YouTube, and a Farsi blog. The DOS believes that $60 \%$ of the Facebook visitors are inside of Iran (Fialho \& Wallin, 2013).

Another area of concern for strategic influence in counter-terrorism and counter-propaganda. Seib (2011) argues that PD can be used to prevent terrorism, acting as a preventative measure. However, he also acknowledges that PD can be used to counter terrorist messages. This is what is commonly known as counter-propaganda, but counter-propaganda does not have to become propaganda itself. In other words, truthfulness and factuality can be used to challenge 
propaganda. This may be a major role that international broadcasting continues. Propaganda and counterpropaganda increasingly come from multiple media sources and ecologies of media (Althiede, 1995; van Dijck \& Poell, 2013). While our news media constantly reminds us of how terrorist groups like ISIL use social media for persuasion and recruiting, we hear little about how populations subjected to terrorist intimidation can use social media to develop resistance forces against the terrorists (Seib, 2011).

\subsection{Persuasion Theory and Social Science}

The model proposed here uses theories from communication studies, psychology, and network science to guide its arguments about influence. The USG uses many theories from science and social science to inform its influence operations, whether they be PD or IO. However, they are argue that there are still many uncertainties as to which approaches work best when attempting various processes of political persuasion.

Larson et al. (2009) present a military model of governmental influence. They call it "influence operations" (p. 5). They correctly note that influence is conducted by three major spheres of the USG-DOD, DOS, and the IC. Two theoretical views adopted by these military scholars are diffusion theory and social network analysis. The former provides useful generalizations about opinion leaders and how interpersonal communication can aid the transmission and acceptance of message. The latter informs the influencers about key network members and how ideas move through networks. They also use the persuasion methods advocated by international relations expert Alexander George. George (2003) recommends that influential third parties, working with moderates rather than hardliners, and encouraging constituents to pressure their leaders are effective means of using direct methods of influence in international situations. George's work is called actor-specific because it argues that influence outcomes depend on characteristics of leaders involved, the nature of their conflict, and various situational factors.

Larson et al. (2009) make note of the many theories of persuasion available for operational use by USG influence experts. These theories include Expectancy Value Theory, the Elaboration Likelihood Model, and Cognitive Dissonance Theory. They argue that many of these theories lack sufficient explanation and prediction of actual behavioral change to be as useful as required by influence operations which attitudes, behaviors, and reason have to be tracked across time to measure dynamical changes in relation to message changes. They note that marketing research suffers from the same application problems as some of the persuasion research, observing, for example, that about half of advertising spending may be wasted on efforts that have little or no desired effects (Larson et al., 2009).

The science of influence that concerns these practitioners is how to influence the decisions that are made by target audience, not in labs, but in complex social and political environments. Thus, they develop a model from multiple theoretical sources to attempt a scientific approach to gaining message entry into social environments and specific persuasive effects for those messages. This is akin to campaign persuasion described by persuasion theorists. The communication involved uses multiple levels of progressive effects and many channels to carry key messages. Their observations are consistent with the need in communication studies to use multi-theory, multi-level approaches to message design (Monge \& Contractor, 2003)

These experts gravitate toward expectancy utility models of influence. Such models are used by IC for persuasion. Their goals include not only influencing positive audiences but also adversarial ones and doing so in ways that account for the complexities of political contexts. For example, where there are two opposing forces and one involves the U.S., they look for actor variables, conflict variables, and situational variables to determine what kinds of diplomacy may or may not work. Their expectancy utility models include data regarding identification of key groups that can exert influence, ranges of policy outcomes, policy preferences, and estimates of how much groups consider various issues. The science of such modeling comes from research done on political decision making, voting behavior, and game theory. Such a model employed in 2002 predicted the U.S. would win the war on Iraq in 2003, that Saddam Hussein would fall, and that a prolonged insurgency would follow (Kugler, Tammen, \& Efird, 2004; Larson, et al., 2009). Snyder (2013) also argues for more reliance on social science when analyzing what might work better in PD.

\subsection{Networking and System Roles for International Broadcasting}

Advocates of new public diplomacy and social media in strategic influence in general, believe that networking is a strong positive alternative to the message transmission approaches of the past, including international broadcasting. During World War II, and the Cold War, it was possible to assume that other populations were in need of more and more accurate information provided by the U.S. and its allies. However, such an assumption of information deficits today may be problematic due to the rapid and widespread of information through the Internet and its multitude of connection technologies. As Joseph Nye (2004) notes, the challenge of transmitting scarce information is thing of the past. Nye also argues that an abundance of information today can actually produce a scarcity of attention. Strong 
critics of public diplomacy today argue that international broadcasting is stuck in past views of influence that were the beginnings of Radio Free Europe and the Voice of America. Robin (2005) makes the crucial point that today the adversaries facing United States are employing open information rather than censorship to confront the U.S. This may suggest the continuous need for both information and counter-information.

Some observers doubt that international broadcasting has a useful role today, in a time far different from the origins of this kind of broadcasting, namely World War II and the Cold War. Wimbash and Portale (2015) argue that the missions among the international broadcasting networks need to be brought into better alignment. Because these networks are part of the USG, they should not try to be like CNN or other government-free sources. Perhaps they can be fair and informative without pretending to be highly objective. Calling the present state of USG international broadcasting "outdated and ineffectual," Wimbash and Portale (2015) argue that the present international broadcasting structure and practices should be terminated (p. 6). Hillary Clinton recently labeled the role of international broadcasting as "defunct" (Wimbash and Portale, 2015, p. 7). Yet, even some of these critics believe that international broadcasting can be reorganized into a useful part of strategic communication and public diplomacy.

Network theory allows us to see how networking can easily trump old schemes for broadcasting. Social media networks can bypass traditional sources of agenda-setting, framing, and control. Traditional broadcasting misses the power of networking with Internet-based connection technologies like smartphone and social media sites.

Both Zaharna and Castells reflect current communication research regarding how people are using horizontal networks to produce both a "connective mindshift" and also new ways of exchanging information and sharing interpretations of events in the world (Zaharna, Fisher, \& Arsenault, 2013, p. 1). Recent descriptions of new media and social media platforms indicate network structures but not what people do those structures (Zaharna, 2013). What they accomplish with those structures is central to the model we propose here. Collaboration by using the structures is new public diplomacy and collaborative diplomacy which serve the objectives of both strategic influence and global engagement.

Communication networks online are only one part of human networks. Another part is constituted by offline communication that is also part of the network formations and interactions. Unlike certain systems that work within organizational boundaries, like political systems, networks can cross all kinds of boundaries, including some cultural ones. As Seib (2012) notes "Technology propels broader social networks" (p. 125). Nodes (people) in a social network not only link to each other but can also link to the people in each other's networks. Thus, one network can be a node in another network (Seib, 2012). Scholars of international politics have observed that nation-state sovereignty remains powerful, yet nation-states are having to work together more due to the expansion of global connectivity and international interdependencies (Slaughter, 2004). When these connections work well, nation-states work on common goals. It is in this historical and political context, that international broadcasting must seek some new roles and sustained relevance.

In the World War II and Cold War days of international broadcasting, messages were pretty much pointto-many and served mainly as propaganda or counterpropaganda. Today, we see that international broadcasting can become more interactive by including more interviews and debates which allows more two-way communication on a traditionally one-way platform. With new media, international broadcasting can also incorporate more interactive Internet-based channels like Twitter, which allow feedback rather than transmission alone.

While some scholars are breathless about PD 2.0, others doubt that it has much utility. Snyder (2013) for example, says that the hoped for effects of social and new media on PD effectiveness have not been demonstrated. He argues "The Internet is an extraordinary tool that has made communications far faster and easier...but its utility in reaching across barriers and biding people to on another-the core hard work of public diplomacy-remains feeble and limited" (p. 92). To experts like Snyder, figures about Twitter followers, Facebook likes and Internet traffic give little information about what is most important for national influence. To cement his argument, he notes that President Obama noted that he has less Facebook friends than Sponge Bob. This does not deny the possible benefits of social media for national influence. Snyder (2013) calls attention to the fact that social media platforms facilitate information sharing.

Still, while new media and social media are fashionable, most people in most countries are more likely to obtain their political information from old media like TV. A 2015 Nielsen report on media usage by in the world ${ }^{14}$ indicates that $76 \%$ of Internet users like being connected anywhere, anytime, as well as $24 / 7$ connectivity (Nielsen, 2015). TV remains popular and online users appear to enjoy using social media to discuss with others what they have viewed on TV (Nielsen, 2015). Apparently, we are in a multiple-screen era as $47 \%$ of the respondents said that they are engaged in social media as they watch TV. As for TV itself, the

\footnotetext{
14 This study used a sample of 300,000 online users in 60 countries. Retrieved from http://www.nielsen.com/content/ dam/corporate/us/en/reports-downloads/2015-reports/totalaudience-report-q1-2015.pdf
} 
study shows that most respondents prefer television sets rather than other devices for viewing video programming.

New interactive roles for international broadcasting are visible the data regarding new media ecologies. Online media like social media can be used to reinforce traditional media transmission. As Snyder (2013) observes "social media, the Internet, and traditional media all reinforce each other" (p. 96). As journalists look to new media for topics and stories, an increasing amount of user-generated content can enter old media agenda-setting processes. Also what is covered in old media can diffuse into social media discussions and debates. Caution of course, is in order, one realizes that only $1 / 3$ of the world's population is actively using the Internet (Snyder, 2013).

\subsection{Applying Network Theory to International Broadcasting}

Much of what is written about the political uses of new media and social media is anecdotal, backed by little systematic empirical analysis, and often devoid of useful theoretical reasoning. For this reason, we offer some basic principles from network theory that can offer a more sophisticated approach to examining international broadcasting roles in new media ecologies. Some scholars have noted the disconnect between national influence theorists and practitioners. Pamment (2013), for example, observes "Whereas theorists of the new PD have tended to point to the normative potential of dialogical and participatory $\mathrm{PD}$, practitioners tend to be motivated by short-term self-interest, and adopt new PD communization models only when it suits them" (p. 127).

Listing new connection technologies like smartphones and chat apps use for political communication is not theory, nor is it science. Inferring persuasion effects from simple exposure to messages has long been exposed in communication studies as fallacious pursuit. Skeptical musings about social media activism by Malcolm Gladwell or Utopian musings by Clay Shirky are interesting, but not explanatory. In contrast, network theory offers specific principles of communication complexity and organization that bring to focus the role of international broadcasting within systems of information flow and social interactions. Despite differences in conclusions about the exact political effects of new media and social media, there is general agreement that these new technologies provide new and emerging forms creating and sharing information as well as connecting to others (Seo, 2013).

There is nothing extraordinary about online information usage, but online social relationship formation across various national and political boundaries opens up opportunities that may involve political networks that share political viewpoints including some that dis- course violence and encourage democracy. To understand more about how social media are associated with behaviors related to democracy, more research is needed about what activities and collaborations are occurring with social media in relation to building or fortifying democracies. Of course, participation is important but participation can be democratic or undemocratic. Topics like Public Diplomacy 2.0 need much more empirical and theoretical analysis. The basic principle of networking and relationships is that people use networks for long-term connections and mutual message exchange. Important aspects of social networks that make them work well to meeting their relational goals are trust, positivity, commitment, and others (Seo, 2013). International broadcasting can enter the complexity of new media systems and ecologies by interconnecting with other channels, both old and new.

Communication networks are complex systems. They cannot be explained by studying single nodes or components. Understanding how a network works required knowledge of the various types of interactivity in the network (Caldarelli \& Catanzaro, 2012). Some parts of a network, such as the international broadcasting component of a media network, can grow in relation to design while others such local social and smallermedia networks may growth through unplanned selforganizing processes. Network theory applied to our model can help to identify where the dynamics of network influence emerge in complex systems of multiple channels and dual purposes (influence, relationships).

One of the most useful findings in network theory research is that of preferential attachment. Preferential attachment refers to new nodes in a network (people in a human network) seeking to link to older nodes with lots of network connectivity (Caldarelli \& Catanzaro, 2012). The older nodes that keep attracting more and new nodes become what are known as hubs (Caldarelli \& Catanzaro, 2012). For old or new media, the more visibility, the more new links that are likely. Sociologists once found that women rated a man in a picture higher when he was surrounded by many other women than when he was alone in the photo. This is an example of the preferential attachment principle (Caldarelli \& Catanzaro, 2012).

Research on political communication done online indicates that people tend to sort themselves into preferred networks. One study, for example, showed that users of Democratic and Republican blogs have few connections to each other across party lines (Caldarelli \& Catanzaro, 2012). In taking advantage of network study findings, professionals working with international broadcasting may be able to take advantage of what is called social spreading, the tendency of people to mimic the behaviors of their social contacts (Caldarelli \& Catanzaro, 2012). Indeed, if smoking and obesity are increased by social networking, it may be expected that political ideas can be as well. 


\section{Conclusions}

When public diplomacy rests on vague notions of soft power and cultural networking, key issues of power, dominance, and manipulation, which affects worldviews of our nation, are continuously glossed or missed. Said differently, appeals to soft power to build more positive American images may be futile when strong negative images are being formed in relation to American use of hard power occurring at the same time. However, this does not mean that soft power obviates the use of hard power, but rather that a dialectic and complex approach to power, communication, and security must guide various forms of strategic influence, including international broadcasting.

Today's communication ecology constitutes what some call a global information sphere or a global communication system. What is done with international broadcasting in this system is not simply a matter of technological challenges, but also challenges of purposes and goals and scholars continue to question how national influence (including public diplomacy) serves national interests and national security concerns. The argument presented here attempts to develop a model linking strategic communication, public diplomacy, and other forms of national influence including strategic influence. The presented model of strategic influence builds in propositions about the need for both assertive and challenging communication and globally engaging networking and shows how international broadcasting can be part of this coordinated effort. Combining or coordinating strategic influence with cultural networking can bring out an alternative to soft diplomacy/soft power and hard diplomacy/hard power dichotomies, and instead offer the alternative of smart power coupled with smart diplomacy. Smart diplomacy uses both strategic influence and networking to serve national security goals as well as goals of international cooperation and global engagement.

The analysis and model construction presented here makes four important contributions to the study and development of national influence efforts. First, we provide some ways of bringing together two domains of national influence that are artificially separated-strategic influence and cultural networking. Second, we use communication theory to produce a new unified model of national influence. Third, we offer the concept of "smart diplomacy" as an analogue to smart power. Fourth, we apply network theory to those aspect of national influence that increasingly involve networking.

As all research projects have limitations, we acknowledge two that appear in our work thus far. First, we have done mainly historical and metatheoretical analysis with few empirical data sets to support our claims. Second, we have not yet cracked the code of how to stop the endless flow of terminolo- gy struggles in the study of SC and PD. Future research should build more on process and less on terminology. Yet determining which process is most important at any point in time will still be debatable.

\section{Acknowledgments}

The authors thank the anonymous reviewers for their stringent and thorough remarks which allowed us to make many necessary changes.

\section{Conflict of Interests}

The author declares no conflict of interests.

\section{References}

Altheide, D. (1995). An ecology of communication. New York: Walter de Gruyter.

Armistead, L. (2010). Information operations matter. Washington, DC: Potomac Books.

Arndt, R. (2005). The first resort of kings: American cultural diplomacy in the twentieth century. Washington, DC: Potomac Books.

Arsenault, A. (2013). Networks of freedom, networks of control. In R. S. Zaharna, A. Arsenault \& A. Fisher (Eds), Relational, networked, and collaborative approaches to public diplomacy: The connective mindshift (pp. 192-208). New York: Routledge.

BBG. (2015). BBG fact sheet. Broadcasting Board of Governors. Retrieved from http://www.bbg.gov/wpcontent/media/2015/03/BBG_Factsheet_v18.pdf

BBG. (2013). Fiscal year 2013 performance and accountability report. Retrieved from http://www.bbg.gov/ wp-content/media/2013/12/BBG-FY-2013-PAR-Finalaccessible.pdf

Bent, S. (1937). International broadcasting. The Public Opinion Quarterly, 3, 117-121.

Block, R. (1948). Propaganda and free society. Public Opinion Quarterly, 12, 677-686.

Caldarelli, G., \& Catanzaro, M. (2012). Networks: A very short introduction. Oxford, UK: Oxford University Press.

Castells, M. (2007). Communication, power, and counter-power in the network society. International Journal of Communication, 1, 238-266.

Castells, M. (2009). Communication power. New York: Oxford.

Castells, M. (2011). A network theory of power. International Journal of Communication, 5, 773-787.

Comor, E., \& Bean, H. (2012). America's "engagement" delusion: Critiquing a public diplomacy consensus. International Communication Gazette, 74, 203-220.

Cull, N. (2009). Public diplomacy before Gullion: The evolution of a phrase. In N. Snow \& P. Taylor (Eds.), Routledge handbook of public diplomacy (pp. 19-23). New York: Routledge. 
Cull, N. (2013). The long road to public diplomacy. International Studies Review, 15, 123-139.

Cull, N. (2014). Evaluating the history of U.S. public diplomacy. Data-driven public diplomacy. Retrieved from http://www.state.gov/documents/organizatio n/231945.pdf

Dizard, W. (2004). Inventing public diplomacy: The story of the United States Information Agency. Boulder: Lynne Rienner.

Doorey, T. (2009). Waging an effective strategic communication campaign in the war on terror. In G. David \& T. McKeldin III (Eds.), Ideas as weapons (pp. 145-161). Washington, DC: Potomac Books.

Entman, R. (2008). Theorizing mediated public diplomacy: The U.S. case. The International Journal of Press/Politics, 13, 87-102.

Fialho, L., \& Wallin, M. (2013). Reaching for an audience: U.S. public diplomacy towards Iran. Washington, DC: American Security Project. Retrieved from https:// www.americansecurityproject.org/ASP\%20Reports/ Ref\%200131\%20-\%20US\%20Public\%20Diplomacy\%2 0Towards\%20Iran.pdf

Freedman, G. (2013). Strategy: A history. New York: Oxford University Press.

George, A. (2003). The need for influence theory and actor-specific behavioral models of adversaries. In B. Schneider \& J.Post (Eds.), Know thy enemy: Profiles of adversary leaders and their strategic cultures (pp. 271-310). Montgomery: Maxwell Air Force Base, USAF Counterproliferation Center.

Golan, G. (2015). An integrated approach to public diplomacy. In G. Golan, S. Yang, \& D. Kinsey (Eds.), International public relations and public diplomacy (pp. 417-440). New York: Peter Lang.

Gray, C. S. (1999). Strategic culture as context: The first generation of theory strikes back. Review of International Studies, 25, 49-69.

Gregory, B. (2008). Public diplomacy: Sunrise of an academic field. The ANNALS of the American Academy of Political and Social Science, 616, 274-290.

Gregory, B. (2014). The paradox of U.S. public diplomacy: Its rise and demise. Washington DC: George Washington University Institute for Public Diplomacy and Global Communication.

Hacker, K., \& van Dijk, J. (Eds.). (2000). Digital democracy: Issues of theory and practice. London: Sage.

Hart, J. (2013). Empire of ideas. New York: Oxford University Press.

Hocking, B. (2007). Rethinking the 'new' public diplomacy. In J. Melissen (Ed.), The new public diplomacy: Soft power in international relations (pp. 28-43). New York: Palgrave MacMillan.

Kennedy, L., \& Lucas, S. (2005). Enduring freedom: Public diplomacy and U.S. foreign policy. American Quarterly, 57, 309-336.

Kugler, J., Tammen, R., \& Efird, B. (2004). Integrating theory and policy: Global implications of the war in
Iraq. International Studies Review, 6, 163-179.

Larson, E., Darilik, R., Gibran, D., Nichiporuk, B., Richardson, A., Schwartz, L., \& Thurston, C. (2009). Foundations of effective influence operations. Santa Monica, CA: RAND Corporation.

Lord, C. (2006). Losing hearts and minds? Westport, CT: Praeger.

Lord, K., \& Lynch, M. (2010). America's extended hand: Assessing the Obama adminstration's global engagement strategy. Washington, DC: Center for a New American Security.

Mahnken, T. (2006). United State strategic culture. Defense Threat Reduction Agency. Retrieved from https://fas.org/irp/agency/dod/dtra/us.pdf

Maloney, S. (2015). Iran's public diplomacy in a vacuum. In G. Wiseman (Ed.), Isolate or engage: Adversarial states, U.S. foreign policy, and public diplomacy (pp. 164-2014). Stanford: Stanford University Press.

Manvell, R., \& Fraenkel, H. (2010). Doctor Goebbels: His life and death. London: Frontline Books.

Mastapeter, C. (2008). The instruments of national power: Achieving strategic advantage for a changing world. Monterey, CA: Naval Postgraduate School.

Melissen, J. (2007). The new public diplomacy: Between theory and practice. In J. Melissen (Ed.), The new public diplomacy: Soft power in international relations (pp. 3-27). New York: Palgrave MacMillan.

Monge, P., \& Contractor, N. (2003). Theories of communication networks. New York: Oxford University Press.

Mullen, M. (2009). Getting back to basics. Joint Forces Quarterly, Issue 55, pp. 2-4.

Nye, J. (2004). Soft power. Cambridge, MA: Perseus Books Group.

Pamment, J. (2013). New public diplomacy in the 21st century. London: Routledge.

Paul, C. (2011). Strategic communication. Santa Barbara, CA: ABC-CLIO.

Perna, R. (2009). The role of background conversations, culture, and a harmonized communications strategy in effecting change. IO Journal, 1(1), 12-17.

Powers, S., \& Samuel-Azran, T. (2015). Conceptualizing international broadcasting as information intervention. In G. Golan, S. Yang, \& D. Kinsey (Eds.), International public relations and public diplomacy (pp. 245264). New York: Peter Lang.

Pratkanis, A., \& Aronson, E. (1991). Age of propaganda. New York: W.H. Freeman.

Price, M. E., Hass, S., \& Margolin, D. (2008). New technologies and international broadcasting: Reflections on adaptations and transformation. The ANNALs of the American Academy of Political and Social Science, $616,150-172$

Robin, R. (2005). Requiem for public diplomacy? American Quarterly, 57, 345-353.

Safire, W. (2001, September 20). Equal time for Hitler? New York Times. Retrieved from http://www.ny 
times.com/2001/09/20/opinion/20SAFI.html

Sandes, B. (2011). American avatar: The United States in the global imagination. Washington, DC: Potomac Books.

Schneder, M. (2015). U.S. public diplomacy since 9/11: The challenges of integration. In G. Golan, S. Yang, \& D. Kinsey (Eds.), International public relations and public diplomacy (pp. 15-36). New York: Peter Lang.

Seib, P. (2007, December 19). New media and public diplomacy: International broadcasting, public diplomacy and cultural exchange. BBC World Service Conference, London.

Seib, P. (2011). Public diplomacy, new media, and counterterrorism. Los Angeles: USC Center on Public Diplomacy.

Seib, P. (2012). Real-time diplomacy: Politics and power in the social media era. New York: Palgrave MacMillan.

Seo, H. (2013). The "Virtual Last Three Feet": Understanding relationship perspectives in network-based public diplomacy. In R. S. Zaharna, A. Arsenault, \& A. Fisher (Eds.), Relational, networked, and collaborative approaches to public diplomacy: The connective mindshift (pp. 157-169). New York: Routledge.

Slaughter, A. (2004). A new world order. Princeton: Princeton University Press.

Snow, N. (2014, August). NHI World and Japanese public diplomacy. RIPE@2014 Conference, Public Service Media across Boundaries, Japan.

Snyder, J. (2013). The United States and the challenge of public diplomacy. New York: Palgrave MacMillan.

Sorenson, T. (2006). We become propagandists. In G. Jowett \& V. O'Donnell (Eds.), Readings in propaganda and persuasion (pp. 83-109). London: Sage.

Taylor, P. (2003). Munitions of the mind. Manchester: Manchester University Press.

Tiedeman, A. (2005). Islamic Republic of Iran broadcasting: Public diplomacy or propaganda? Fletcher Online Journal for Issues Related to Southwest Asia and Islamic Civilization, Spring, 1-7.

Tuch, H. (1990). Communicating with the world. New York: St. Martin's Press.
Tufan, F. (2014). New possibilities provided by social networks to radio broadcasting Practices: R@adio 2.0. Journal of Media Critiques, 1, 87-101.

Van Dijk, J. (2012). The network society. London: Sage.

van Dijck, J., \& Poell, T. (2013). Understanding social media logic. Media and Communication, 1, 2-14.

Waller, J. (2008). Strategic influence: Public diplomacy, counter-propaganda, and political warfare. Washington, DC: The Institute of World Politics Press.

Waller, J. (2009). Getting serious about strategic influence. Center for Security Policy Occasional Paper. Retrieved from https://www.centerforsecuritypolicy. org/upload/wysiwyg/center\%20publication\%20pdfs/ Michael\%20Waller\%20-\%20Getting\%20Serious\%20 About\%20Strategic\%20Influence.pdf

Weed, M. (2014). U.S. international broadcasting: Background and issues for reform. Washington, DC: Congressional Research Service.

White House (2010). National framework for strategic communication. Retrieved from http://fas.org/man/ eprint/pubdip.pdf

Wimbush, E., \& Portale, E. (2015). Reassessing U.S. international broadcasting. Retrieved from http:// www.wilsoncenter.org/sites/default/files/WimbushP ortaleFINAL\%20REPORT\%20international\%20bdcstin g.pdf

Youmans, W., \& Powers, S. (2012). Remote negotiations: International broadcasting in the information age. International Journal of Communication, 6, 2149-2172.

Zaharna, R. S. (2010). From battles to bridges. London: Palgrave-McMillan.

Zaharna, R. S. (2013). Network purpose, network design: Dimensions of network and collaborative public diplomacy. In R. S. Zaharna, A. Arsenault, \& A. Fisher (Eds.), Relational, networked, and collaborative approaches to public diplomacy (pp. 173-191). New York: Routledge.

Zaharna, R. S., Fisher, A., \& Arsenault, A. (2013). The connectionist mindshift. In R. S. Zaharna, A. Arsenault, \& A. Fisher (Eds.), Relational, networked, and collaborative approaches to public diplomacy (pp. 114). New York: Routledge.

\section{About the Authors}

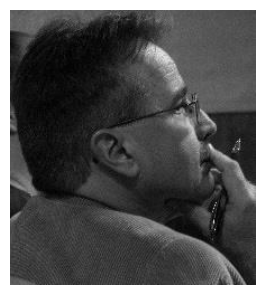

Dr. Kenneth L. Hacker

Kenneth L. Hacker is Professor and Department Head of Communication Studies at New Mexico State University, USA. He is currently working on a book with Jan van Dijk (University of Twente, The Netherlands) called Democracy in a Network Society. This book is planned for release in 2016. He has published numerous journal articles and book chapters on the topics of new media and political communication. These include the book (with Jan van Dijk) Digital Democracy and two edited volumes concerning candidate images in American presidential elections. 


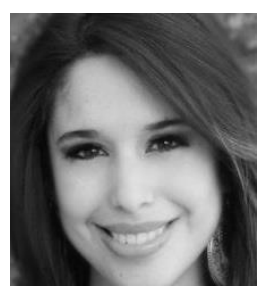

\section{Vanessa R. Mendez}

Ms. Vanessa R. Mendez is a graduate student in the Department of Communication Studies at New Mexico State University. Her research and teaching interests include culture, network communication, and interpersonal communication. She will graduate in May, 2016 with minors in Communication and National Security and Higher Educational Leadership Administration. 